\title{
Body mass index and asthma severity in the National Asthma Survey
}

\author{
B Taylor, ${ }^{1}$ D Mannino, ${ }^{2}$ C Brown, ${ }^{3}$ D Crocker, ${ }^{3}$ N Twum-Baah, ${ }^{1}$ F Holguin ${ }^{1}$
}

\begin{abstract}
${ }^{1}$ Emory University, Atlanta, Georgia, USA; ${ }^{2}$ University of Kentucky, Lexington, Kentucky, USA: ${ }^{3}$ Centers for Disease Control and Prevention, Atlanta, Georgia, USA

Correspondence to:

Dr F Holguin, Clinical Research

Center, Emory Crawford Long

Hospital, 550 Peachtree St,

Davis-Fischer Building, Room

2331, Atlanta, GA 30308, USA;

fch5@cdc.gov
\end{abstract}

Received 13 April 2007 Accepted 5 July 2007

\section{ABSTRACT}

Background: The association between obesity and asthma severity remains controversial and limited to small studies.

Methods: We determined the association of body mass index (BMI) and asthma severity in the National Asthma Survey. We included adults (age $\geqslant 18$ years) who selfreported symptoms of asthma in the past 5 years. A total of 3095 patients were divided into the following BMI categories: 1080 (35\%) non-overweight (BMl <25), 993 $(32 \%)$ overweight $(\mathrm{BMI} \geqslant 25$ and $<30)$ and $1022(33 \%)$ obese (BMI $\geqslant 30)$. Asthma severity measures included respiratory symptoms, healthcare utilisation, medication use, missed work days and the Global Initiative for Asthma (GINA) severity classification. Models were adjusted for: gender, race, age, education, income, employment status, smoking status, family history of asthma, state of residence and residence in a metropolitan statistical area.

Results: Compared with non-overweight subjects, obese subjects with asthma were more likely to report continuous symptoms (OR 1.66, 95\% $\mathrm{Cl} 1.09$ to 2.54), miss more work days (OR $1.35,95 \% \mathrm{Cl} 1.01$ to 1.81 ), use short acting beta agonists (OR 1.36, 95\% Cl 1.06 to 1.75 ), use inhaled corticosteroids (OR 1.34, 95\% Cl 1.01 to 1.79 ) and use any controller medication according to GINA guidelines (OR 1.37, 95\% Cl 1.01 to 1.85). Also, obese respondents were less likely to be in asthma remission (OR $0.56,95 \% \mathrm{Cl} 0.38$ to 0.82 ) and were more likely to have severe persistent asthma (GINA IV) (OR 1.42, 95\% Cl 1.05 to 1.90).

Conclusions: In a large, diverse sample of adults with asthma, obesity was associated with measures of asthma severity after adjusting for potential confounders.

Approximately $65 \%$ of adults in the USA aged 20 years or older are either overweight or obese, ${ }^{1}$ which is a $10 \%$ increase in obesity prevalence from the previous decade. ${ }^{2}$ Similar to the obesity epidemic, there has also been a substantial increase in the prevalence of asthma in the USA. ${ }^{4}$ Concurrent with the parallel increase in asthma and obesity prevalence, many studies have reported associations between obesity and higher asthma prevalence rates. ${ }^{5-11}$ This association is substantiated by evidence showing obesity as a risk factor for incident asthma, ${ }^{12-17}$ data which were recently strengthened by a meta-analysis confirming this association..$^{18}$ Further, obesity has also been associated with bronchial hyperresponsiveness. ${ }^{19-21}$ Finally, a number of studies have demonstrated that weight loss can improve both physiological and clinical parameters of asthma. ${ }^{22-24}$

More recently, obesity has been recognised as a potential risk factor for asthma severity, ${ }^{25-29}$ poor asthma control and lower asthma related quality of life..$^{30}$ However, this association remains controversial because of the limited patient populations included in earlier studies, ${ }^{25-29}$ inconsistent definitions for asthma severity ${ }^{29}$ and lack of statistical significance after adjusting for potential confounders. $^{30}$

Preliminary data further suggest that obese patients with asthma demonstrate both different asthma genotypes compared with patients of normal weight ${ }^{26}$ and diminished response to current asthma therapy. ${ }^{31}{ }^{22}$ Definitive demonstration of an association between obesity and asthma severity would lend further support to the notion of a different phenotype among obese patients with asthma and may lead researchers to consider novel approaches to asthma therapy in this population.

Therefore, to further understand how obesity may impact asthma severity, we examined the association of body mass index (BMI) with the following measures of severity: respiratory symptoms, healthcare utilisation, medication usage, missed work days and asthma severity classification. We conducted this study using data from the four state sample of the National Asthma Survey (NAS), one of the largest, diverse surveys of all asthma patients in the USA.

\section{METHODS}

The NAS, sponsored by the National Center for Environmental Health, Centers for Disease Control and Prevention, is divided into two samples: a national sample consisting of 8621 respondents (only 934 of whom reported asthma) designed to primarily examine the prevalence of asthma and a four state sample consisting of 5741 respondents (all of whom reported asthma) designed to investigate factors related to asthma control. We utilised the four state survey of self-reported, physician diagnosed patients with asthma. Conducted between 1 March 2003 to 10 March 2004 in four target states, Alabama, California, Illinois and Texas, the project used a State and Local Area Integrated Telephone Survey (SLAITS) design, using the same sampling frame as the CDC's National Immunisation Survey. Data were collected using a computer assisted telephone interview system. SLAITS used a complex multistage, stratified survey of civilian, non-institutionalised populations with telephones. The response rate of the Council of American Survey Research Organisations (CASRO) reported for the four state NAS sample was $49.6 \%$ (http://www.casro.org/ resprates.cfm). This was calculated as the product 
of the resolution, screener completion and interview completion rates.

Participating households were screened for the presence of any members with asthma. In asthma positive households, a maximum of one adult and one child per household were selected, with adults and children sampled separately. Because the definitions of overweight and obese differ between children and adults, we restricted our analysis to adult participants (age $\geqslant 18$ years) who self-reported height and weight. We also excluded patients who reported neither asthma symptoms nor asthma medication use in the past 5 years in order to minimise the impact of patients with a distant history of asthma, in particular those with asthma as a child but not as an adult.

\section{Questionnaire}

From the NAS questionnaire we obtained the following variables.

\section{Asthma}

Our case definition of asthma consisted of a positive response to the following question: "Including yourself, has anyone living in your household ever been told by a doctor or other health professional that they have asthma?" We excluded patients who demonstrated prolonged remission, defined as neither asthma symptoms nor medication use in the past 5 years.

\section{Body mass index}

BMI was defined as weight in kilograms divided by height in metres squared and was categorised into three groups: nonoverweight (BMI $<25)$, overweight $(\mathrm{BMI} \geqslant 25$ and $<30)$ and obese $(\mathrm{BMI} \geqslant 30)$. As only 52 respondents $(1.7 \%)$ included in our analysis fell into the underweight classification (defined as BMI $<18.5$ ), we did not further separate out this subgroup.

\section{Covariates}

We included gender, race/ethnicity (white (non-Hispanic), black (non-Hispanic), Hispanic and other), age group (18-24, 25-44, 45-64, 65+ years), smoking status (current, former, never), education level $(<12$ th grade, high school graduate, some college, college graduate or higher), income (<US\$25k, US\$25k-44 999, US\$45k-74 999, $\geqslant$ US\$75k), employment status (full time, part time, and unemployed-excluding participants unemployed by choice), family history of asthma (defined as a parent with asthma), state of residence (Alabama, California, Illinois, Texas) and residence in a metropolitan statistical area (area with a population of at least 500 000, based on each participant's home ZIP code).

\section{Asthma control and severity measures}

Outcomes measures for asthma control and severity were divided into the following categories: respiratory symptoms (daytime and night-time symptoms in the past 30 days, asthma attacks in the past 90 days and presence of continuous respiratory symptoms in the 30 days prior to the interview), healthcare utilisation (emergency room, urgent care centre and other unscheduled doctor visits for asthma in the past 12 months), missed work days and medication use. From these questions, we also derived each participant's GINA (Global Initiative for Asthma, symptoms only) severity class. ${ }^{33}$ If respondents reported no medication use or symptoms of asthma in the past year, they were classified as in remission. ${ }^{34}$ Medication use was evaluated for the 90 day period immediately preceding the survey and was divided into the following categories: short acting $\beta_{2}$ agonist, long acting beta agonist, anticholinergic, methylxanthine, leucotriene modifier, cromolyn, inhaled corticosteroid and oral corticosteroid. As we also had information on corticosteroid dosing, we classified patients on inhaled corticosteroids into low dose $(\leqslant 400 \mathrm{mg} /$ day budesonide equivalent), medium dose (401-800 mg/day budesonide equivalent) or high dose (>800 mg/day budesonide equivalent). ${ }^{33}$ This allowed us to further classify each respondent's medication regimen by step of therapy according to GINA guidelines. ${ }^{33}$ We were unable to accurately differentiate between GINA steps 3 and 4 because dosing information was not available for respondents taking medications that combined fluticasone and salmeterol; therefore, these steps were grouped together in our analysis.

\section{Analysis}

Initially, we compared the distribution of the covariates and outcomes across BMI categories. To test for differences in the distribution of proportions, we used the $\chi^{2}$ test and for continuous normally distributed data, we used the one way ANOVA test. Next, we developed a multivariable logistic regression analysis to test the association of BMI categories with measures of asthma control and severity using nonoverweight subjects as the reference. We adjusted the models for the following potential confounders: age, gender, smoking status, race, income category, education category, employment status, family history of asthma, state of residence and metropolitan statistical area. Because prior studies have suggested gender differences in the association of obesity and asthma severity, ${ }^{29}{ }^{30}$ we included a BMI and gender interaction term in the multivariable analysis.

Variance estimates were adjusted for the complex survey design (Proc Survey logistic; SAS, Cary, North Caroline, USA) by using weighted data provided with NAS, using state of residence for strata and identification number for cluster. The weights used to arrive at these estimates were person-level final weights for only sample adults 18 years of age. These final weights incorporated a base sampling weight, an adjustment for multiple telephone lines within a household and various adjustments for non-response. Each final weight was then post-stratified so that the sum of weights for each state equalled the selected population control totals from the 2003 Behaviour Risk Factor Surveillance System data for that state (http:// www.cdc.gov/brfss/). We used SAS 9.1.3 to perform these analyses.

\section{RESULTS}

Out of a total of 5741 participants, 2646 respondents were excluded for the following reasons: 10 lacked data for age, 2003 respondents were children under the age of 18 years, 371 were adults who reported prolonged remission and 262 did not provide height and/or weight information.

The demographic characteristics of the weighted study population across BMI categories are presented in table 1. Obese respondents were more likely to be women, AfricanAmerican and have a lower socioeconomic status. We found no significant differences with regard to smoking status and family history of asthma.

Results from the univariable analysis of measures of asthma control and severity are presented in table 2. Obesity was associated with more respiratory symptoms, more frequent emergency room and urgent physician visits, increased missed work days, greater use of short acting beta agonists and higher 
Table 1 Characteristics of the study population by body mass index categories $\dagger$

\begin{tabular}{|c|c|c|c|c|}
\hline & $\begin{array}{l}\text { Non-overweight } \\
\text { (BMI <25) } \\
\text { (n (weighted \%†)) }\end{array}$ & $\begin{array}{l}\text { Overweight } \\
(25 \leqslant \mathrm{BMI}<30) \\
\text { (n (weighted \%)) }\end{array}$ & $\begin{array}{l}\text { Obese } \\
\text { (BMI } \geqslant 30) \\
\text { (n (weighted \%)) }\end{array}$ & p Value \\
\hline \multicolumn{5}{|l|}{ Gender } \\
\hline Male & $294(30)^{*}$ & $398(43)$ & $291(27)$ & \\
\hline Female & $786(38)^{*}$ & $595(28)$ & $731(34)$ & $<0.01$ \\
\hline \multicolumn{5}{|l|}{ Race/ethnicity } \\
\hline White, non-Hispanic & $814(38)^{*}$ & $682(33)^{*}$ & $675(29)^{*}$ & \\
\hline African-American, non-Hispanic & $93(30)^{*}$ & $109(28)^{*}$ & $154(42)^{*}$ & \\
\hline Hispanic & $104(32)^{*}$ & $113(35)^{*}$ & $126(33)^{*}$ & \\
\hline Other & $58(27)^{*}$ & $76(43)^{*}$ & $58(30)^{*}$ & 0.01 \\
\hline \multicolumn{5}{|l|}{ Age (y) } \\
\hline $18-24$ & $192(50)$ & $101(29)$ & $70(21)$ & \\
\hline $25-44$ & $422(34)$ & $370(33)$ & $390(33)$ & \\
\hline $45-64$ & $347(29)$ & $365(35)$ & $445(36)$ & \\
\hline $65+$ & $119(31)$ & $157(42)$ & $117(27)$ & $<0.01$ \\
\hline \multicolumn{5}{|l|}{ Smoking status } \\
\hline Current-every day & $145(40)^{*}$ & $110(29)^{*}$ & $137(31)^{*}$ & \\
\hline Current —some days & $69(44)^{*}$ & $52(32)^{*}$ & $54(24)^{*}$ & \\
\hline Past smoker & $269(31)^{*}$ & $289(38)^{*}$ & $270(31)^{*}$ & \\
\hline Never smoker & $591(35)^{*}$ & $541(34)^{*}$ & $559(31)^{*}$ & 0.10 \\
\hline \multicolumn{5}{|l|}{ Education } \\
\hline Less than 12 th grade & $112(32)$ & $98(30)$ & $159(38)^{*}$ & \\
\hline High school graduate & $243(27)$ & $260(37)$ & $294(36)^{*}$ & \\
\hline Some college & $282(38)$ & $278(31)$ & $278(31)^{*}$ & \\
\hline College grad + & $443(40)$ & $357(36)$ & $288(24)^{*}$ & $<0.01$ \\
\hline \multicolumn{5}{|l|}{ Income (US\$) } \\
\hline$<25000$ & $384(35)$ & $347(29)$ & $470(36)$ & \\
\hline $25000-44999$ & $191(31)$ & $186(36)$ & $187(33)$ & \\
\hline $45000-74999$ & $199(33)$ & $210(39)$ & $191(28)$ & \\
\hline$\geqslant 75000$ & $306(38)$ & $250(38)$ & $174(24)$ & $<0.01$ \\
\hline \multicolumn{5}{|l|}{ Employment status } \\
\hline Full time & $477(33)^{*}$ & $498(37)^{*}$ & $460(30)^{*}$ & \\
\hline Part time & $155(42)^{*}$ & $120(31)^{*}$ & $108(27)^{*}$ & \\
\hline Unemployed (by choice) & $260(39)^{*}$ & $209(36)^{*}$ & $159(25)^{*}$ & \\
\hline Unemployed & $184(32)^{*}$ & $163(27)^{*}$ & $292(41)^{*}$ & $<0.01$ \\
\hline \multicolumn{5}{|l|}{ Parent with asthma } \\
\hline Yes & $275(34)$ & $270(33)$ & $291(33)$ & \\
\hline No & $754(35)$ & $671(35)$ & $670(30)$ & \\
\hline Don't know & $51(36)$ & $52(33)$ & $61(31)$ & 0.92 \\
\hline \multicolumn{5}{|l|}{ State of residence } \\
\hline Alabama & $268(34)$ & $235(29)$ & $305(37)$ & \\
\hline California & $282(36)$ & $264(35)$ & $221(29)$ & \\
\hline Illinois & $255(32)$ & $236(32)$ & $255(36)$ & \\
\hline Texas & $275(36)$ & $258(33)$ & $241(31)$ & 0.03 \\
\hline \multicolumn{5}{|c|}{ Residence in a metropolitan statistical area } \\
\hline Yes & $918(29)^{*}$ & $817(35)^{*}$ & $796(36)^{*}$ & \\
\hline No & $152(36)^{*}$ & $171(34)^{*}$ & $221(30)^{*}$ & 0.10 \\
\hline
\end{tabular}

GINA severity classification. Underweight respondents did not demonstrate an increase in markers of asthma control or severity when compared with normal weight subjects; however, very few underweight adults participated in the study (data not shown).

As seen in table 3, many of these results persist after adjustment for all covariables through multivariable logistic regression analysis, using non-overweight respondents as the reference category. Obese respondents were significantly more likely to report symptoms all of the time, miss more days of work and use both short acting $\beta_{2}$ agonists and inhaled corticosteroids. When respondent's medication regimens were categorised into steps of therapy per GINA guidelines, obese respondents were also more likely to use controller medications (GINA medication step 2 or greater). Finally, obese respondents were less likely to be in asthma remission and were more likely to be classified as persistent asthma (GINA class II-IV) and/or severe persistent asthma (GINA class IV).

Because prior studies had found significant gender differences when examining the impact of obesity on measures of asthma control and severity, ${ }^{29}{ }^{30}$ we repeated the multivariable logistic models for all of the outcomes in table 3 with the addition of an 
Table 2 Distribution of asthma severity outcomes and medications by body mass index category

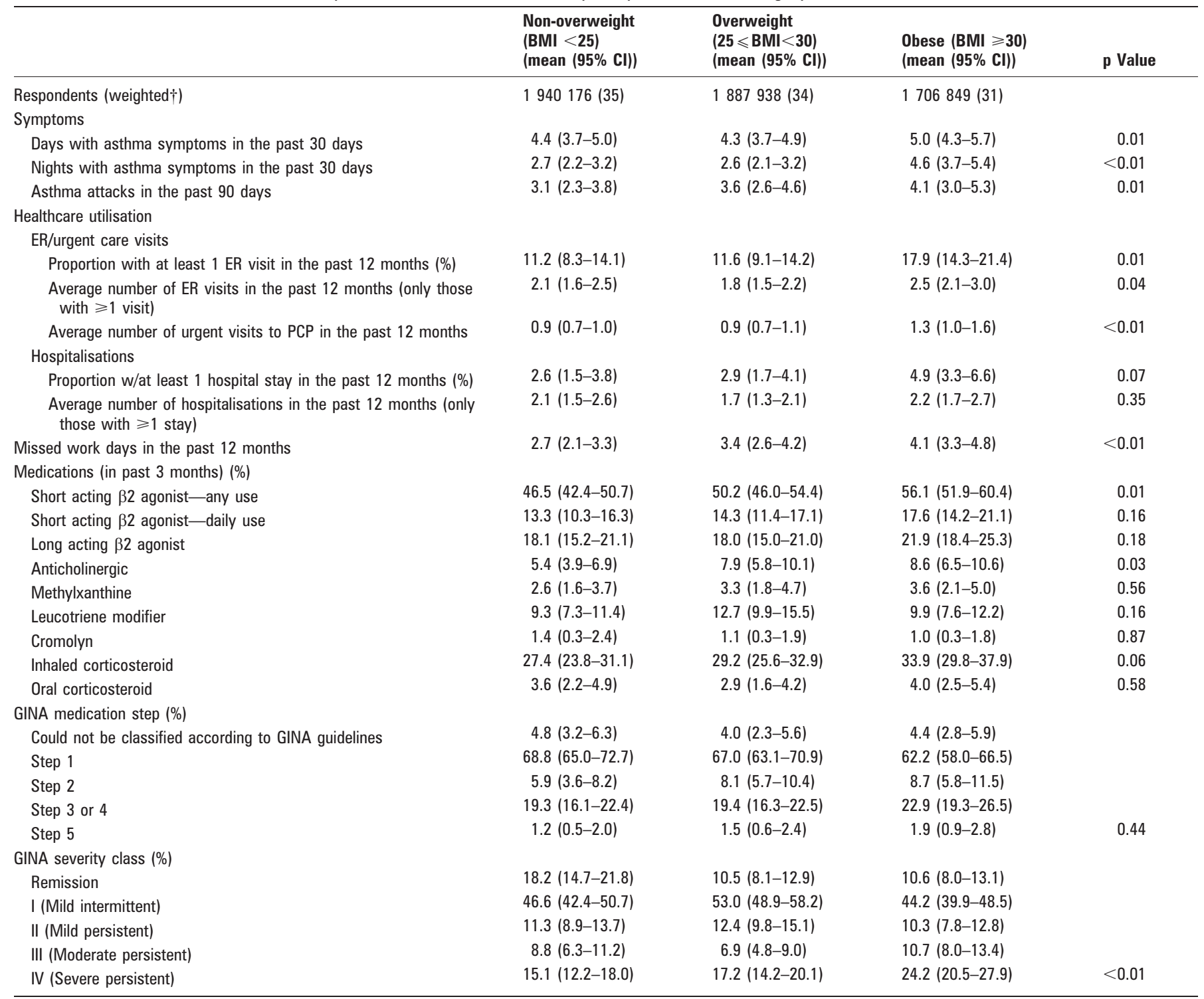

$\mathrm{p}$ Values determined using the $\chi^{2}$ test for distribution of proportions and the one way ANOVA test for continuous normally distributed data.

$\mathrm{BMI}$, body mass index; ER, emergency room; GINA, Global Initiative for Asthma Guidelines; PCP, primary care provider.

interaction term for gender and BMI. For all outcomes examined, we found no significant interaction between BMI and gender.

\section{DISCUSSION}

In the four state sample of the National Asthma Survey, one of the largest asthma surveys in the USA, we showed that obesity is associated with several measures of asthma severity and control, including symptoms, missed work days, medication use and GINA severity classification. To our knowledge, this is one of the most comprehensive and largest all-asthma surveys showing the association between asthma severity and obesity using a broad range of severity outcomes.

While the majority of studies support an association between obesity and asthma prevalence, ${ }^{5-11}$ the literature examining obesity and asthma severity is more controversial. Inconsistencies across published studies may relate to several limiting factors, including small study sizes, variable asthma definitions and different asthma severity outcomes.
A few studies to date have demonstrated an association between obesity and increased asthma severity classification in adults $^{25} 28$; however, each has had significant limitations. For example, Akerman et al demonstrated an increased likelihood of obesity among adults with both moderate and severe persistent asthma compared with adults with mild intermittent asthma using the 1997 National Heart, Lung, and Blood Institute guidelines for asthma severity. ${ }^{25}$ However, this study included only 143 patients, did not examine other potentially important markers of severity that were examined in our analysis and was performed in an inner city asthma clinic, therefore limiting its external validity. Similarly, Saint-Pierre et al demonstrated that patients with severe persistent asthma were more likely to be overweight (defined as BMI $\geqslant 25$ ) compared with those with mild persistent and moderate persistent asthma. ${ }^{28}$ However, important limitations in this study included relatively small sample size (406 patients) and lack of distinction between overweight and obese categories.

Further evidence supporting an association between asthma severity and obesity was a case control and family study 
Table 3 Multivariable logistic analysis for asthma severity outcomes

\begin{tabular}{|c|c|c|}
\hline & \multicolumn{2}{|c|}{$\begin{array}{l}\text { OR (compared with non-overweight patients-BMI } \\
\leqslant 25)\end{array}$} \\
\hline & $\begin{array}{l}\text { Overweight } \\
(25 \leqslant \mathrm{BMI}<30) \\
\text { OR }(95 \% \mathrm{Cl})\end{array}$ & $\begin{array}{l}\text { Obese } \\
\text { (BMI } \geqslant 30) \\
\text { OR }(95 \% \mathrm{CI})\end{array}$ \\
\hline \multicolumn{3}{|l|}{ Symptoms } \\
\hline Greater than 4 days with asthma symptoms in the past 30 days* & $1.05(0.80-1.38)$ & $0.95(0.71-1.26)$ \\
\hline Greater than 2 nights with asthma symptoms in the past 30 days* & $0.94(0.69-1.28)$ & $1.31(0.97-1.78)$ \\
\hline Greater than 2 asthma attacks in the past 90 days* & $0.87(0.64-1.18)$ & $1.02(0.74-1.40)$ \\
\hline Any asthma attacks in the past 90 days & $1.19(0.93-1.54)$ & $1.18(0.91-1.54)$ \\
\hline Symptoms all the time over the past 30 days & $1.21(0.80-1.83)$ & $1.66(1.09-2.54)$ \\
\hline \multicolumn{3}{|l|}{ Healthcare utilisation } \\
\hline At least $1 \mathrm{ER}$ visit in the past 12 months* & $1.17(0.79-1.74)$ & $1.45(0.99-2.12)$ \\
\hline Greater than 1 urgent visit to PCP in the past 12 months* & $0.95(0.69-1.29)$ & $1.16(0.84-1.61)$ \\
\hline At least 1 hospitalisation in the past 12 months* & $1.22(0.65-2.28)$ & $1.43(0.79-2.60)$ \\
\hline Greater than 2 missed work days in the past 12 months* & $1.01(0.75-1.37)$ & $1.35(1.01-1.81)$ \\
\hline \multicolumn{3}{|l|}{ Medications (in past 3 months) } \\
\hline Short acting $\beta 2$ agonist—any use & $1.21(0.94-1.54)$ & $1.36(1.06-1.75)$ \\
\hline Short acting $\beta 2$ agonist—daily use & $1.11(0.76-1.61)$ & $1.20(0.85-1.69)$ \\
\hline Long acting $\beta 2$ agonist & $0.92(0.68-1.25)$ & $1.20(0.88-1.65)$ \\
\hline Anticholinergic & $1.37(0.88-2.15)$ & $1.26(0.83-1.90)$ \\
\hline Methylxanthine & $0.96(0.49-1.85)$ & $0.89(0.46-1.72)$ \\
\hline Leucotriene modifier & $1.42(0.97-2.08)$ & $0.96(0.65-1.43)$ \\
\hline Cromolyn & $0.99(0.39-2.50)$ & $0.63(0.23-1.72)$ \\
\hline Inhaled corticosteroid & $1.06(0.81-1.40)$ & $1.34(1.01-1.79)$ \\
\hline Oral corticosteroid & $0.69(0.37-1.27)$ & $0.72(0.40-1.32)$ \\
\hline GINA step 1 (SABA only) & $0.98(0.75-1.28)$ & $0.81(0.60-1.07)$ \\
\hline GINA step $2+$ & $1.09(0.83-1.45)$ & $1.37(1.01-1.85)$ \\
\hline \multicolumn{3}{|l|}{ GINA severity classification } \\
\hline Remission & $0.53(0.36-0.76)$ & $0.56(0.38-0.82)$ \\
\hline Mild intermittent (class I) & $1.28(1.00-1.65)$ & $1.00(0.77-1.29)$ \\
\hline Persistent asthma (class II-IV) & $1.07(0.82-1.39)$ & $1.35(1.03-1.76)$ \\
\hline Severe persistent (class IV) & $0.95(0.71-1.28)$ & $1.42(1.05-1.90)$ \\
\hline
\end{tabular}

published by Varraso and colleagues. ${ }^{29}$ This study examined 366 patients aged 16 years and older, of whom 189 were male and 177 female. Using a compounded severity score derived from participants' self-reported frequency of asthma attacks, persistence of symptoms between attacks and hospitalisations for asthma, they found a significant association between BMI and an increased severity in women but not men, which persisted after adjusting for age, smoking status, forced expiratory volume in $1 \mathrm{~s}$ and degree of bronchial hyperresponsiveness. Unfortunately, because of the small number of males enrolled, this study lacked power to detect associations in this group. Further, because a validated categorisation system to ascertain asthma severity was not employed, these results cannot be adequately compared with other similar studies.

Others studies have failed to demonstrate associations between obesity and asthma severity. ${ }^{27} 3035$ In a 9 year European longitudinal study, de Marco et al showed no difference in baseline BMI across asthma severity groups using GINA severity classification. ${ }^{27}$ However, during follow-up, patients who achieved asthma remission were the ones likely to gain the least amount of weight. Lavoie et al demonstrated that obese adults with asthma had significantly poorer asthma control, asthma quality of life and were also more likely to use long acting $\beta_{2}$ agonists $^{30}$; however, these associations did not persist in multivariate analysis.
In a cohort of 572 adults with asthma presenting to 26 emergency departments in the USA and Canada with acute asthma symptoms, Thomson et al showed no difference in either the clinical presentation or emergency department course across BMI groups. ${ }^{35}$ However, the authors reported a nonsignificant trend towards more severe asthma symptoms, greater $\beta_{2}$ agonist use and greater inhaled corticosteroid use among obese patients compared with those of normal BMI. With only 572 patients, this study may not have had sufficient power to detect significant differences in asthma severity outcomes. More importantly, because obese patients are often older than their non-obese counterparts, ${ }^{30} 35$ by excluding patients 55 years and older, this study potentially eliminated a significant number of study subjects.

Our analysis represents a significant advance compared with previous literature, and addresses a number of important limitations that have characterised previous studies. First, by using an asthma study population three times greater in size than any prior study, we had greater statistical power to detect small differences in severity and control measures across BMI groups. Second, because our results stem from a survey of a diverse patient population, these results are more likely to be generalisable to the general population.

A number of studies have demonstrated a significant gender difference in the interaction between obesity and asthma, with most suggesting that the association of obesity with both 
asthma prevalence and incidence is significantly stronger in women than in men. ${ }^{512} 14$ Further, Chen et al showed that obesity is more strongly associated with non-allergic asthma compared with allergic asthma ${ }^{36}$; non-allergic asthma is more prevalent in women than in men, ${ }^{37}$ suggesting a potential explanation for gender related differences. Few studies have examined gender differences in the association between asthma severity and obesity, but some early evidence suggests that this association is also stronger in women. ${ }^{29}$ However, this finding has not held true in all studies. For example, Lavoie et al found that men had a significantly sharper decline in asthma quality of life scores as BMI increased..$^{30}$ Further, studies examining the association of BMI with bronchial hyperresponsiveness have suggested that men, rather than women, show significantly more bronchial hyperresponsiveness as BMI increases, ${ }^{19}{ }^{20}$ which may help explain Lavoie's data. However, our data do not support a gender interaction between obesity and asthma severity.

When interpreting our findings, certain limitations should be considered. First, because of its cross sectional design, we are unable to demonstrate causality; this is an important limitation given that our analysis cannot differentiate between respondents who gained weight because of severe asthma versus those whose asthma is severe because they are obese. Second, our study relied on both self-reported anthropometric data and selfreported physician diagnosed asthma, both of which could bias the results. Self-reported height and weight may lead to underestimation of obesity prevalence as it is widely believed that men tend to overestimate height and women tend to underestimate weight. However, in validation studies, selfreported height and weight correlate well among both genders, ${ }^{38}$ even in groups thought to have the highest risk of reporting bias. ${ }^{39}$ Further, in studies of asthma prevalence or incidence, using measured height and weight yields similar findings compared with studies using self-reported height and weight. $^{912} 15$

Third, our asthma case definition is based on physician diagnosed asthma, which may be the source of misclassification bias, as recently outlined by Ford. ${ }^{40}$ Bias may be due to potential under diagnosis of asthma in non-obese patients as well as misdiagnosis of asthma in obese patients. As discussed by Ford, ${ }^{40}$ under diagnosis is unlikely to lead to significant changes in prevalence estimates but it is conceivable that the effects of misdiagnosis of asthma in the obese could have a relatively large effect. However, in a large longitudinal study using a more strict definition of asthma to study the effects of obesity on asthma incidence, ${ }^{13}$ findings were similar to those studies using less rigorous definitions for asthma, suggesting that potential effects of this bias may be overestimated. Fourth, another potential limitation of our study is the absence of spirometry data in establishing GINA severity classification; however, it is unlikely that this would result in differential bias with regard to BMI categories.

Recently, the emphasis of asthma care has shifted to the evaluation of and attempt to achieve and maintain asthma control rather than focusing on asthma severity. The recently published GINA guidelines use daytime and night-time symptoms, use of rescue medications, limitation of activity, forced expiratory volume in $1 \mathrm{~s}$ or peak expiratory flow, and occurrence of asthma exacerbations to classify patients as controlled, partially controlled or uncontrolled. ${ }^{33}$ We analysed many of these outcomes in our assessment of asthma severity. Our desire was to classify patients into one of the three control classifications. However, because information for many of these variables was obtained over different time frames (ie, the minimum resolution for symptoms was for the past 30 days whereas resolution for limitation to activity was 1 year), we were unable to derive validated asthma GINA control classifications. Therefore, we focused on severity classification instead.

In summary, we have demonstrated a significant association between asthma severity and obesity using a large, diverse population of adults with asthma, after adjusting for a number of potential confounders. These results, coupled with data suggesting genotypic differences in obese patients with asthma ${ }^{26}$ and reduced response to standard asthma therapy compared with non-obese patients with asthma, ${ }^{31}{ }^{32}$ strongly support the notion that obesity could lead to a more severe asthma phenotype. Clearly, many questions remain to be answered, including how much weight must be gained to increase asthma severity? What constitutes the "asthma phenotype"? Obviously, not every adult with asthma who becomes obese develops more severe disease. Therefore, understanding what genetic and environmental factors render a patient with asthma susceptible to the effects of obesity is an important question that should be answered in prospective clinical trials.

Although causation between obesity and asthma severity remains controversial from a biological mechanistic perspective, it is clear that obesity is associated with increased respiratory symptoms, healthcare utilisation and poorer quality of life. Further, prior data demonstrates improvement in a number of parameters of asthma associated with weight loss. ${ }^{22-24}$ Thus asthma treatment guidelines should aggressively pursue weight control as an integral part of their treatment strategy.

Funding: Supported by the CDC (Air Pollution Respiratory Health branch) and ORISE fellowship (Oakridge Institute for Science and Education). Research also supported by NIH/NCRR K12 RR017643.

Competing interests: None.

\section{REFERENCES}

1. Hedley AA, Ogden CL, Johnson CL, et al. Prevalence of overweight and obesity among US children, adolescents, and adults, 1999-2002. JAMA 2004;291:2847-50.

2. Flegal KM, Carroll MD, Kuczmarski RJ, et al. Overweight and obesity in the United States: prevalence and trends, 1960-1994. Int J Obes Relat Metab Disord 1998;22:39-47.

3. Self-reported asthma prevalence and control among adults-United States, 2001. MMWR Morb Mortal Wkly Rep 2003;52:381-4.

4. Mannino DM, Homa DM, Akinbami LJ, et al. Surveillance for asthma-United States, 1980-1999. MMWR Surveill Summ 2002;51:1-13.

5. Chen $\mathbf{Y}$, Dales $\mathrm{R}$, Krewski D, et al. Increased effects of smoking and obesity on asthma among female Canadians: the National Population Health Survey, 1994-1995. Am J Epidemiol 1999;150:255-62.

6. Huovinen E, Kaprio J, Koskenvuo M. Factors associated to lifestyle and risk of adult onset asthma. Respir Med 2003;97:273-80.

7. Luder $\mathbf{E}$, Ehrlich RI, Lou WY, et al. Body mass index and the risk of asthma in adults. Respir Med 2004;98:29-37.

8. Nystad W, Meyer HE, Nafstad P, et al. Body mass index in relation to adult asthma among 135,000 Norwegian men and women. Am J Epidemiol 2004;160:969-76.

9. Shaheen So, Sterne JA, Montgomery SM, et al. Birth weight, body mass index and asthma in young adults. Thorax 1999;54:396-402.

10. Stanley AH, Demissie K, Rhoads GG. Asthma development with obesity exposure: observations from the cohort of the National Health and Nutrition Evaluation Survey Epidemiologic Follow-up Study (NHEFS). J Asthma 2005;42:97-9.

11. Young SY, Gunzenhauser JD, Malone KE, et al. Body mass index and asthma in the military population of the northwestern United States. Arch Intern Med 2001:161:1605-11.

12. Beckett WS, Jacobs DR Jr, Yu X, et al. Asthma is associated with weight gain in females but not males, independent of physical activity. Am J Respir Crit Care Med 2001;164:2045-50.

13. Camargo CA Jr, Weiss ST, Zhang S, et al. Prospective study of body mass index weight change, and risk of adult-onset asthma in women. Arch Intern Med 1999;159:2582-8

14. Chen Y, Dales R, Tang M, et al. Obesity may increase the incidence of asthma in women but not in men: longitudinal observations from the Canadian National Population Health Surveys. Am J Epidemiol 2002;155:191-7.

15. Guerra S, Sherrill DL, Bobadilla A, et al. The relation of body mass index to asthma chronic bronchitis, and emphysema. Chest 2002;122:1256-63. 
16. Ronmark E, Andersson C, Nystrom L, et al. Obesity increases the risk of incident asthma among adults. Eur Respir J 2005;25:282-8.

17. Beuther DA, Weiss ST, Sutherland ER. Obesity and asthma. Am J Respir Crit Care Med 2006:174:112-19.

18. Beuther DA, Sutherland ER. Overweight, obesity and incident asthma: a metaanalysis of prospective epidemiologic studies. Am J Respir Crit Care Med 2007;175:661-6.

19. Chinn S, Jarvis D, Burney P. Relation of bronchial responsiveness to body mass index in the ECRHS. European Community Respiratory Health Survey. Thorax 2002;57:1028-33.

20. Litonjua AA, Sparrow D, Celedon JC, et al. Association of body mass index with the development of methacholine airway hyperresponsiveness in men: the Normative Aging Study. Thorax 2002;57:581-5.

21. Sood A, Verhulst SJ, Varma A, et al. Association of excess weight and degree of airway responsiveness in asthmatics and non-asthmatics. J Asthma 2006;43:44752.

22. Hakala K, Stenius-Aarniala B, Sovijarvi A. Effects of weight loss on peak flow variability, airways obstruction, and lung volumes in obese patients with asthma. Chest 2000;118:1315-21.

23. Aaron SD, Fergusson D, Dent $R$, et al. Effect of weight reduction on respiratory function and airway reactivity in obese women. Chest 2004;125:2046-52.

24. Stenius-Aarniala B, Poussa T, Kvarnstrom J, et al. Immediate and long term effects of weight reduction in obese people with asthma: randomised controlled study. BMJ 2000;320:827-32.

25. Akerman MJ, Calacanis CM, Madsen MK. Relationship between asthma severity and obesity. J Asthma 2004;41:521-6.

26. Barr RG, Cooper DM, Speizer FE, et al. Beta(2)-adrenoceptor polymorphism and body mass index are associated with adult-onset asthma in sedentary but not active women. Chest 2001;120:1474-9.

27. de Marco R, Marcon A, Jarvis D, et al. Prognostic factors of asthma severity: a 9year international prospective cohort study. J Allergy Clin Immunol 2006;117:124956 .
28. Saint-Pierre $\mathbf{P}$, Bourdin A, Chanez $\mathrm{P}$, et al. Are overweight asthmatics more difficult to control? Allergy 2006;61:79-84.

29. Varraso R, Siroux V, Maccario J, et al. Asthma severity is associated with body mass index and early menarche in women. Am J Respir Crit Care Med 2005; 171:334-9.

30. Lavoie KL, Bacon SL, Labrecque M, et al. Higher BMI is associated with worse asthma control and quality of life but not asthma severity. Respir Med 2006; 100:648-57.

31. Dixon AE, Shade DM, Cohen Rl, et al. Effect of obesity on clinical presentation and response to treatment in asthma. J Asthma 2006;43:553-8.

32. Peters-Golden M, Swern A, Bird SS, et al. Influence of body mass index on the response to asthma controller agents. Eur Respir J 2006;27:495-503.

33. Global Initiative for asthma (GINA) 2006. Available from http://www.ginasthma.com (accessed 16 November 2007).

34. van den Toorn LM, Prins JB, Overbeek SE, et al. Adolescents in clinical remission of atopic asthma have elevated exhaled nitric oxide levels and bronchial hyperresponsiveness. Am J Respir Crit Care Med 2000;162 (3 Pt 1):953-7.

35. Thomson CC, Clark S, Camargo CA Jr. Body mass index and asthma severity among adults presenting to the emergency department. Chest 2003; 124:795-802.

36. Chen Y, Dales R, Jiang Y. The association between obesity and asthma is stronger in nonallergic than allergic adults. Chest 2006;130:890-5.

37. Romanet-Manent S, Charpin D, Magnan A, et al. Allergic vs nonallergic asthma: what makes the difference? Allergy 2002;57:607-13.

38. Rimm EB, Stampfer MJ, Colditz GA, et al. Validity of self-reported waist and hip circumferences in men and women. Epidemiology 1990;1:466-73.

39. Troy LMM, Hunter DJ, Manson JE, et al. The validity of recalled weight among younger women. Int J Obes Relat Metab Disord 1995; 19:570-2.

40. Ford ES. The epidemiology of obesity and asthma. J Allergy Clin Immunol 2005;115:897-909.

\section{Lung alert}

\section{Neoadjuvant chemotherapy in operable non-small cell lung cancer}

Survival for patients with non-small cell lung cancer (NSCLC) has remained unchanged for over 10 years. This randomised controlled trial assessed the benefits of neoadjuvant chemotherapy in patients with operable NSCLC.

519 patients were randomised to receive surgery as soon as possible or chemotherapy as soon as possible followed by surgery 4-6 weeks from day 1 of the last chemotherapy cycle. Patients with stage I-III disease were included. The primary outcome measure was overall survival, and secondary outcome measures included quality of life, clinical and pathological staging, resectability rates, extent of surgery, and the time to and site of relapse.

There was no difference in overall survival between the two treatment groups. $31 \%$ of patients receiving chemotherapy before surgery were down-staged at the time of surgery; however, this did not alter the type of surgery they had. A very small proportion of patients progressed during chemotherapy. Surgery did not appear to be affected by the time taken to deliver neoadjuvant chemotherapy. With regard to baseline symptoms and quality of life, neoadjuvant chemotherapy had a minimal effect. Patterns of recurrence and progression were also not affected by chemotherapy except for the fact that more of the patients who underwent chemotherapy before surgery developed brain metastases.

This trial did not show any survival benefit with neoadjuvant chemotherapy, which is largely consistent with results from previous trials.

- Gilligan D, Nicolson M, Smith I, et al, on behalf of the trial collaborators. Preoperative chemotherapy in patients with resectable nonsmall cell lung cancer: results of the MRC LU22/ NVALT 2/ EORTC 08012 multicentre randomised trial and update of systematic review. Lancet 2007;369:1929-37

\section{J Gittens}

Correspondence to: J Gittens, ST2, QE II Hospital, Welwyn Garden City, Herts, UK; jonson72@fsmail.net 